\title{
Hyponatremia Etiology and Tolvaptan: Are we Optimally Targeting the Mechanism?
}

\author{
Arif Asif ${ }^{*}, 1$, Ketan Ghate ${ }^{1}$, Neena Jube ${ }^{1}$, Syed S. Haqqie ${ }^{1}$, Roy O. Mathew ${ }^{1,2}$, Vishesh Kumar ${ }^{1}$, \\ John Tietjen ${ }^{3}$, John Rosenberger ${ }^{4}$, Sunil Pokharel ${ }^{3}$, Syed F. Saeed ${ }^{3}$, Shervin Yousefian ${ }^{3}$, \\ Donna Merrill $^{1}$, Rizwan Shahid ${ }^{5}$, Muhammad U.T. Akmal ${ }^{5}$, Ali Nayer ${ }^{5}$, Darius Mason ${ }^{1}$, \\ Tushar Vachharajani ${ }^{6}$ and Loay Salman ${ }^{5}$
}

\author{
${ }^{I}$ Division of Nephrology and Hypertension, Albany Medical College, Albany, NY, USA \\ ${ }^{2}$ Stratton VA Medical Center, Albany, NY, USA \\ ${ }^{3}$ Division of Hospital Medicine, Albany Medical College, Albany, NY, USA \\ ${ }^{4}$ Division of General Medicine, Albany Medical College, Albany, NY, USA \\ ${ }^{5}$ Division of Nephrology and Hypertension, University of Miami Miller School of Medicine, Miami, FL, USA \\ ${ }^{6}$ Division of Nephrology and Hypertension, W.G. (Bill) Hefner Veterans Affairs Medical Center, Salisbury, NC, USA
}

\begin{abstract}
Hyponatremia is associated with increased morbidity and mortality. Water restriction is usually the prescribed treatment for most forms of asymptomatic hyponatremia. An oral vasopressin V2-receptor antagonist, tolvaptan has been successfully used in the treatment of asymptomatic hyponatremia. In this retrospective study, tolvaptan $(n=40)$ and a control group $(n=40)$ were compared for asymptomatic hyponatremia etiology and response to treatment. The syndrome of inappropriate anti-diuretic hormone (SIADH) and congestive heart failure (CHF) were the most common causes of asymptomatic hyponatremia that were treated with tolvaptan. Of note, the cause of hyponatremia was not clarified in $50 \%$ of the control and $10 \%$ of the tolvaptan group. In the tolvaptan group, serum sodium concentration increased from $125 \pm 4.2$ to $136 \pm 2.1 \mathrm{mEq} / \mathrm{L}$ (mean $\pm \mathrm{SD}, \mathrm{P}<0.001$ ) over $5 \pm 2$ days while the control group did not show any change from its baseline value of $129.9 \pm 3$ vs $128 \pm 4 \mathrm{mEq} / \mathrm{L}$. SIADH and CHF were the most common disorders associated with asymptomatic hyponatremia and treated with tolvaptan. Importantly, $50 \%$ of the asymptomatic hyponatremia patients in the control group were labeled as unclear etiology and did not receive tolvaptan. Increased awareness of the etiology and mechanisms of asymptomatic hyponatremia development can identify individuals who benefit from tolvaptan therapy.
\end{abstract}

Keywords: Hyponatremia, serum osmolality, serum sodium, tolvaptan, urine osmolality.

\section{INTRODUCTION}

Hyponatremia is the most common electrolyte disturbance that is encountered in hospitalized patients. Nearly $25 \%$ of the hospitalized patients and $30 \%$ of the patients in intensive care units develop hyponatremia [1,2]. Asymptomatic hyponatremia defined as a serum sodium concentration $<135 \mathrm{mEq} / \mathrm{L}$ without altered mental status, lethargy, nausea, vomiting, imbalance or seizures is associated with increased morbidity and mortality $[1,2]$. In addition, hyponatremia imposes a huge economic burden on the cost of medical care. A recent analysis of 168,000 patients from 39 medical centers revealed that the one-year cost of medical care for patients with normal $(>135 \mathrm{mEq} / \mathrm{L})$ serum sodium concentration was $\$ 9,257$ versus $\$ 19,215$ for those with hyponatremia [3].

*Address correspondence to this author at the Thomas Ordway Distinguished Professor of Medicine, Chief: Division of Nephrology and Hypertension, Albany Medical College, 25 Hacket Blvd, Albany, NY 12208, USA; Tel: 518-262-0769; E-mail: AsifA@mail.amc.edu
Restriction of water intake is the usual treatment for asymptomatic hyponatremia. Recently, two large multicenter randomized trials demonstrated that tolvaptan, an oral vasopressin V2-receptor antagonist, could increase serum sodium concentration to the normal range [4].

In this retrospective study, we investigated the characteristics of patients with asymptomatic hyponatremia treated with tolvaptan and compared them to a control group of patients with asymptomatic hyponatremia who did not receive tolvaptan.

\section{METHODS}

We conducted a retrospective chart review of hospitalized patients with asymptomatic hyponatremia (serum sodium concentration less than $135 \mathrm{mEq} / \mathrm{L}$ ) who were treated with tolvaptan over a one-year period. Demographic characteristics and etiology of asymptomatic hyponatremia were investigated. The dose and duration of tolvaptan therapy were evaluated and the change in serum sodium concentration was recorded. A control group of patients with 
asymptomatic hyponatremia in whom water restriction was prescribed was identified over the same time frame of one year. Demographic characteristics, etiology and change in serum sodium concentration for the control group were also documented. The data were recorded retrospectively. The institutional review board approved the study. All study procedures were carried out in accordance with the Declaration of Helsinki regarding research involving human subjects.

Data are expressed as mean \pm standard deviation (SD). Comparison of continuous variables between pre- and postmeasurements was performed using paired t-test. The $p$ value was considered significant if $<0.05$. All statistical analyses were done using Microsoft Excel (Redmond, WA).

\section{RESULTS}

40 patients with asymptomatic hyponatremia who received tolvaptan were identified. A cohort of another 40 patients with asymptomatic hyponatremia served as the control group. Demographics of patients are presented in Table 1. Most patients were elderly ( $>60$ years) and Caucasian (80\%). $55 \%$ of the patients in the tolvaptan group and $62 \%$ in the control group were male. Neither body weight nor body mass index differed between the groups.

Table 2 presents the etiology of hyponatremia. The syndrome of inappropriate anti-diuretic hormone (SIADH) was significantly more prevalent in the tolvaptan group than in the control group (57.5\% vs $12.5 \%$; $\mathrm{P}<0.001)$ (Fig. 1).
Similarly, congestive heart failure (CHF) was significantly more prevalent in the tolvaptan group than in the control cohort $(22.5 \% \quad$ vs $2.5 \% ; \quad \mathrm{P}<0.01)$. Asymptomatic hyponatremia of unclear etiology was significantly more common in the control group than in the tolvaptan group $(50 \%$ vs $12.5 \% ; \mathrm{P}<0.001)$. An analysis of the unclear etiology patients in the control group revealed that $16 / 20$ patients had a serum sodium concentration of $127 \pm 3 \mathrm{mEq} / \mathrm{L}$, serum osmolality of $276 \pm 3 \mathrm{mOsmol} / \mathrm{kg} \mathrm{H} \mathrm{H}_{2} \mathrm{O}$, urinary sodium of $71.2 \pm 5 \mathrm{mEq} / \mathrm{L}$ and urine osmolality of $398 \pm 3 \mathrm{mOsmol} / \mathrm{kg}$ $\mathrm{H}_{2} \mathrm{O}$; findings that are consistent with the diagnosis of SIADH (Table 3).

Table 1. Demographic characteristics of the patients.

\begin{tabular}{|c|c|c|c|}
\hline & $\begin{array}{c}\text { Tolvaptan } \\
\text { Group } \\
(\mathbf{n}=\mathbf{4 0})\end{array}$ & $\begin{array}{c}\text { Control } \\
\text { Group } \\
(\mathbf{n = 4 0 )}\end{array}$ & \\
\hline \hline Age (years) & $71.4 \pm 3$ & $64.5 \pm 4$ & NS \\
\hline Body Mass Index & 27.5 & 25.9 & NS \\
\hline Female & $18(45)$ & $15(38)$ & NS \\
\hline Male & $22(55)$ & $25(62)$ & NS \\
\hline White & $33(82)$ & $36(90)$ & NS \\
\hline Black & $4(10)$ & $3(7)$ & NS \\
\hline Hispanic & $2(5)$ & $0(0)$ & NS \\
\hline Asian & $1(3)$ & $1(3)$ & NS \\
\hline
\end{tabular}

NOTE. NS ( $\mathrm{p}$ value not significant).

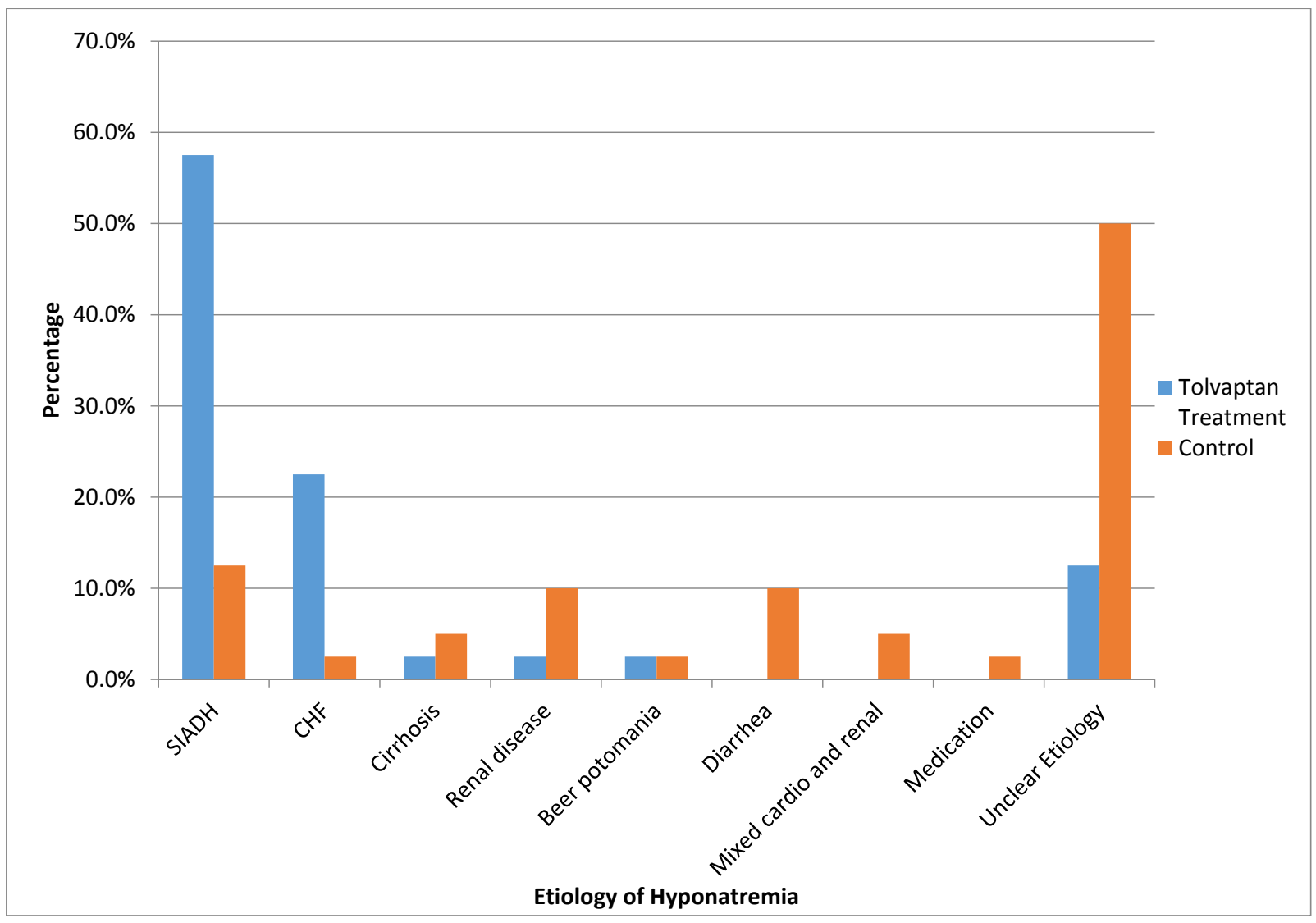

Fig. (1). Various etiologies of hyponatremia in the tolvaptan and control group are highlighted. 
Table 2. Causes of hyponatremia in the tolvaptan and control group.

\begin{tabular}{|c|c|c|c|}
\hline Cause of Hyponatremia & $\begin{array}{c}\text { Tolvaptan } \\
\text { Group } \\
\text { Number (\%) }\end{array}$ & $\begin{array}{c}\text { Control } \\
\text { Group } \\
\text { Number (\%) }\end{array}$ & \\
\hline \hline SIADH & $23(57.5)$ & $5(12.5)$ & $(\mathrm{p}<0.001)$ \\
\hline CHF & $9(22.5)$ & $1(2.5)$ & $(\mathrm{p}<0.01)$ \\
\hline Cirrhosis & $1(2.5)$ & $2(5.0)$ & NS \\
\hline Renal disease & $1(2.5)$ & $4(10.0)$ & NS \\
\hline Beer potomania & $1(2.5)$ & $1(2.5)$ & NS \\
\hline Diarrhea & $0(0.0)$ & $4(10.0)$ & NS \\
\hline Mixed cardio and renal & $0(0.0)$ & $2(5.0)$ & NS \\
\hline Medication & $0(0.0)$ & $1(2.5)$ & NS \\
\hline Unclear Etiology & $5(12.5)$ & $20(50.0)$ & $(\mathrm{p}<0.001)$ \\
\hline Total & $40(100)$ & $40(100)$ & \\
\hline
\end{tabular}

Table 3. Diagnostic considerations for syndrome of inappropriate antidiuretic hormone.

\begin{tabular}{|c|}
\hline $\begin{array}{c}\text { Decreased effective osmolality of the extra-cellular fluid } \\
\bullet \quad \text { Plasma osmolality }<275 \mathrm{mOsmol} / \mathrm{kg} \mathrm{H} \mathrm{H}_{2} \mathrm{O}\end{array}$ \\
\hline $\begin{array}{c}\text { Inappropriate urinary concentration } \\
\text { Urine osmolality }>100 \mathrm{mOsmol} / \mathrm{kg} \mathrm{H}_{2} \mathrm{O} \text { with normal renal } \\
\text { function }\end{array}$ \\
$\begin{array}{c}\text { Clinical euvolemia } \\
\text { No signs of hypovolemia or hypervolemia on clinical } \\
\text { examination }\end{array}$ \\
\hline Elevated urinary sodium excretion despite normal sodium and water intake \\
\hline $\begin{array}{c}\text { No other potential causes of euvolemic hypoosmolality } \\
\text { No hypothyroidism, hypocortisolism or diuretic use }\end{array}$ \\
\hline
\end{tabular}

Thirty-eight patients in the tolvaptan group received the drug at $15 \mathrm{mg} /$ day. In only two patients, the dose was increased to $30 \mathrm{mg} / \mathrm{day}$ to achieve the desired serum sodium concentration of greater than $135 \mathrm{mEq} / \mathrm{L}$. While water restriction was stated in the treatment plan for patients in the control group, a specific order to restrict water was found in only $20 \%(8 / 40)$ of the patients (water restriction to less than $1.0 \mathrm{~L} /$ day). The basis for water restriction to this level was not provided. Whereas serum sodium concentration increased from $125 \pm 4.2$ to $136 \pm 2.1 \mathrm{mEq} / \mathrm{L}(\mathrm{P}<0.001)$ over $5 \pm 2$ days in the tolvaptan group, it did not significantly change in controls (from $129.9 \pm 3$ to $128 \pm 4 \mathrm{mEq} / \mathrm{L}$ ).

\section{DISCUSSION}

The current study finds SIADH and CHF to be the main conditions associated with asymptomatic hyponatremia in our cohort. The present report also highlights appropriate use of an arginine vasopressin antagonist in the tolvaptan group as $80 \%$ of the patients in the tolvaptan group received the drug for hyponatremia in the context of SIADH and CHF. Consistent with the findings of the largest randomized study that evaluated tolvaptan for the treatment of hyponatremia, we showed that tolvaptan led to a significant improvement in serum sodium concentration [4]. Of note, $95 \%$ of the patients required only $15 \mathrm{mg}$ /day of tolvaptan for 5 days to correct hyponatremia. Serum sodium concentration did not change in the control group. While only $15 \%$ of the patients were diagnosed with SIADH (12.5\%) or CHF (2.5\%), hyponatremia of unclear etiology was documented in $50 \%$ of the patients in the control group (Table 2).

A high prevalence of hyponatremia of unclear etiology was an important finding in the control group. Nonetheless, the diagnostic workup including sodium concentration and osmolality in the serum and urine in $80 \%$ of the patients pointed to possibility of SIADH in this unclear etiology cohort (Table 3). Therefore, educational seminars and better awareness of the etiology of hyponatremia will improve the recognition and management of SIADH. These patients might have benefited from tolvaptan therapy. Only one patient in the tolvaptan group had liver cirrhosis. This was before the FDA issued a warning to avoid tolvaptan in the treatment of hyponatremia in patients with liver cirrhosis [5].

It is important to determine the etiology of hyponatremia so that appropriate therapy can be instituted. For instance, depletional hyponatremia (where the condition is due to sodium loss and volume contraction such as diarrhea, vomiting, burns, pancreatitis, cerebral salt wasting) should not be treated with tolvaptan or fluid restriction. On the other hand, SIADH and CHF are the conditions where tolvaptan can be of help. When tolvaptan is used, water restriction should be avoided [4]. It is worth mentioning that the diagnosis of SIADH can be challenging (Table 3) [6]. Clinical assessment (physical examination), laboratory analysis, the context in which hyponatremia is encountered (co-morbid conditions) and the use of medications associated with hyponatremia must be carefully reviewed before SIADH can be excluded. The control group of the current study presents the possibility where the diagnosis of SIADH might have been overlooked and the opportunity to correct serum sodium concentration lost.

While water restriction is often prescribed for patients with a symptomatic hyponatremia, the amount of water allowed per day is usually not specified or calculated. For example, only $20 \%$ of patients in the control group in our study had a specific order for water restriction. In addition, none of them showed a concrete basis supporting $1.0 \mathrm{~L} /$ day of water restriction. It is worth mentioning that water allowance per day for patients with asymptomatic hyponatremia can be calculated using urinary sodium, potassium and serum sodium concentration using a simple calculation [7]. Such a calculation can also indicate whether water restriction is feasible in a given patient. Although the amount of water allowance per day can be calculated, adherence to water restriction is often difficult to achieve. It is important to mention that a small sample size and retrospective design of the study were some of the limitations of the present report.

\section{CONCLUSION}

Hyponatremia in hospitalized patients is commonly secondary to SIADH and CHF and can be successfully 
treated with tolvaptan. Depletional hyponatremia and hyponatremia as a result of liver cirrhosis should not be treated with tolvaptan. Increased awareness of the etiology and mechanisms of hyponatremia can identify patients that can benefit from tolvaptan therapy.

\section{CONFLICT OF INTEREST}

The authors confirm that this article content has no conflict of interest.

\section{ACKNOWLEDGEMENTS}

This project was not funded by grants, funding agencies or any pharmaceutical support. This study was accepted in an abstract form for presentation at the annual scientific meeting of the National Kidney Foundation 2014, Las Vegas, NV, USA.

\section{REFERENCES}

[1] Hawkins RC. Age and gender as risk factors for hyponatremia and hypernatremia. Clin Chim Acta 2003; 337: 169-72.

[2] Verbalis JG, Goldsmith SR, Greenberg A, Schrier RW, Sterns RH. Hyponatremia treatment guidelines 2007: expert panel recommendations. Am J Med 2007; 120: S1-21.

[3] Shea AM, Hammill BG, Curtis LH, Szczech LA, Schulman KA. Medical costs of abnormal serum sodium levels. J Am Soc Nephrol 2008; 19: 764-70.

[4] Schrier RW, Gross P, Gheorghiade M, et al. Tolvaptan, a selective oral vasopressin V2-receptor antagonist, for hyponatremia. N Engl J Med 2006; 355: 2099-112.

[5] http://www.fda.gov/Safety/MedWatch/SafetyInformation/SafetyAl ertsforHumanMedicalProducts/ucm350185.htm

[6] Ellison DH, Berl T. Clinical practice. The syndrome of inappropriate antidiuresis. NEJM 2007; 356: 2064-72.

[7] Furst H, Hallows KR, Post J, et al. The urine/plasma electrolyte ratio: a predictive guide to water restriction. Am J Med Sci 2000; 319: $240-4$.

This is an open access article licensed under the terms of the Creative Commons Attribution Non-Commercial License (http://creativecommons.org/licenses/by-nc/3.0/) which permits unrestricted, non-commercial use, distribution and reproduction in any medium, provided the work is properly cited. 